Notfall Rettungsmed $2013 \cdot 16: 424-426$

DOI 10.1007/s10049-013-1739-1

Online publiziert: 4. Oktober 2013

๑) Springer-Verlag Berlin Heidelberg 2013

\author{
D. Chamberlain ${ }^{1}$ A.J. Handley ${ }^{2}$ \\ ${ }^{1}$ Hove \\ ${ }^{2}$ Colchester
}

\title{
The founding, role, and development of ILCOR
}

The International Liaison Committee on Resuscitation (ILCOR) is an interdisciplinary medical advisory group that has almost unparalleled global representation. It was conceived in February 1992 at the Fifth National Conference on Cardiopulmonary Care in Dallas, Texas. The American Heart Association hosted the meeting, and through the generosity of that organization more than $25 \%$ of delegates came from outside the United States. They represented 25 countries and 53 international organizations. Many of the individuals who participated had previously worked together to set up 'Utstein style' international consensus statements for uniform reporting of data relating to out-of-hospital cardiac arrest, later expanded to cover other collaborative ventures. This experience greatly facilitated the discussions in Dallas. The decision to set up a permanent group emerged during the discussion of a session on International Issues chaired by Richard Cummins and Douglas Chamberlain. After the suggestion had been made, it was warmly endorsed by the meeting as a whole, and immediately seen as a means for setting common international guidelines on cardiopulmonary resuscitation (CPR) and emergency cardiac care (ECC). Representation was not restricted to North America, Europe, and Australia but soon included multidisciplinary societies or councils from Latin America, Africa, and Asia. By 1999, representatives from China, Taiwan, Thailand, Japan, and Malaysia were welcomed to attend meetings. Few inhabited parts of the world do not have full representation or at least close links at the present time. The group was originally called simply the 'Liaison Committee on CPR' but Walter Kloek of South Africa later made the suggestion of the current title; others appreciated the link implied by the acronym ILCOR to the concept of 'sick heart'!

The first independent meeting of the Committee was held in England following an ERC meeting, and the second after a congress in Vienna at which the formal mission statement was adopted:

To provide a consensus mechanism by which the international science and knowledge relevant to emergency cardiac care can be identified and reviewed. This consensus mechanism will be used to provide consistent international guidelines on emergency cardiac care for Basic Life Support (BLS), Paediatric Life Support (PLS) and Advanced Life Support (ALS). While the major focus will be upon treatment guidelines, the steering committee will also address the effectiveness of educational and training approaches and topics related to the organisation and implementation of emergency cardiac care. The Committee will also encourage coordination of dates for guidelines development and conferences by various national resuscitation councils. These international guidelines will aim for a commonality supported by science for BLS, ALS and PLS.

The first Advisory Statements (deliberately not 'guidelines') were published in 1997 in both Circulation and Resuscitation having been prepared by three main working groups: Basic Life Support, chaired by Tony Handley (UK), Advanced Life Sup- 
port, chaired by Walter Kloek (Southern Africa), and Paediatric Life Support, chaired by Vinay Nadkarni (USA). In addition, there was an advisory statement on special resuscitation situations published under the authorship of the members of ILCOR in general. The aim was to produce universal algorithms that could be used for practical guidance in the management of cardiac arrest. These were achieved by discussion and consensus within the working groups, rather than any formal review of published literature.

The rather informal nature of the working groups could not guarantee that recommendations were based on the best available evidence, rather than expert opinion. To address this, a much more structured approach was introduced from 1997 to 2000. This involved evidencebased review and revision of the existing guidelines by experts using specially prepared worksheets, evaluating current science; levels of evidence were allotted to all new material. The process included two Evidence Evaluation Conferences in 1999, and a Guideline 2000 Conference in Dallas in February 2000. The resulting Consensus on Science was prepared by an international editorial board, and again published jointly in Circulation and Resuscitation that same year.

From 2000 onwards, ILCOR has met about twice a year, usually once in the US and once in one of the other member countries, often in association with a major national resuscitation conference. The objective at that time was to publish recommendations every five years. Permanent task forces were created to manage the process of evidence evaluation: basic life support; advanced life support; paediatric life support; neonatal life support; acute coronary syndrome; interdisciplinary [to cover overlapping topics and education and later termed 'education, implementation, and teams' (EIT)]. Two additional topics, first aid and stroke, were not included as official ILCOR task forces, but were run in parallel with the evidence-based process by the American Red Cross and American Heart Association respectively.

In addition to the 5-yearly consensus process, ILCOR has published a number of 'consensus', or 'advisory' statements on the use of hypothermia after cardiac arrest (2003); the use of AEDs in children (2003); and the post-cardiac arrest syndrome (2008). There has also been an ILCOR symposium on 'Education in Resuscitation' held in 2001. The organization also retains a strong association and influence with the Utstein process as befits its origin.

The title of the major 5-yearly ILCOR publications has changed subtly over the years. In 1997, the term 'Advisory Statements' was used. In 2000, this had been extended to 'Guidelines 2000 for Cardiopulmonary Resuscitation and Emergency Cardiovascular Care: International Consensus on Science. In 2005 and 2010 the term 'guidelines' was dropped in favour of 'treatment recommendations', the full title being 'International Consensus on Cardiopulmonary Resuscitation and Emergency Cardiovascular Care Science With Treatment Recommendations', and the acronym CoSTR (pronounced co-star) was born. In 2010, the process was further refined with use of the PICO (Population, Intervention, Comparison, Outcome) convention for uniform structure of worksheet questions.

The principle reason for a change in tithe to 'Consensus' was the understanding that local factors must impact on practice; in matters of detail, what is appropriate in one part of the world is not necessarily exactly appropriate for another. Nevertheless, the objective that various national organizations should coordinate their own guidelines to fit with the timetable of ILCOR has been successful by and large, though inevitably variable delays occur before a new international consensus can translate into changes at a more local level. Sometimes, this is a 2-stage process, as in the United Kingdom where guidelines set by the European Resuscitation Council then have to pass down to the Resuscitation Council (UK), though cooperation and individuals being common to both ensure that publication can be near simultaneous.

The number of international experts has inevitably increased markedly. For the 2005 Consensus, a total of 281 experts completed 403 worksheets on 276 topics, and for the 2010 update, 509 experts completed 569 worksheets on 277 topics.
Clearly, regular face-to-face meetings are not practicable during the process of reviewing evidence, but final joint discussions are held for those who can attend. In 2005, 249 experts, from 18 countries were able to meet in Dallas; for 2010, the numbers had risen to 313 experts from 30 countries.

Consensus statements must make recommendations that have an important impact on the pharmaceutical and device companies world wide. In 2004, ILCOR introduced a rigorous conflict of interest policy to manage 'any real or potential conflicts of interest in an open and effective manner. Each worksheet author and attendee at conferences since then has had to complete a conflict of interest statement and refer to this when giving a presentation. Two senior clinicians, one from the US and one from Europe, were tasked with ensuring that the ILCOR policy was adhered to, and were available to resolve any concerns or disagreements.

The current membership comprises: American Heart Association (AHA); European Resuscitation Council (ERC); Heart and Stroke Foundation of Canada (HSFC); Australian and New Zealand Committee on Resuscitation (ANZCOR); Resuscitation Councils of Southern Africa (RCSA); Inter-American Heart Foundation (IAHF); Resuscitation Council of Asia (RCA - current members Japan, Korea, Singapore, Taiwan). At the early meetings, Latin America had separate representation (CLAR) but this became incorporated into IAHF.

The future of ILCOR seems secure. The need for such a group is fully recognized internationally and its influence is considerable in all topics relating to resuscitation and emergency cardiac care. No doubt it will continue to evolve. Many feel that the 5-yearly intervals between major statements is inappropriately long given the pace at which new evidence unfolds. It may be that more frequent statements less widely based will be a recipe for the future. However its function may change, ILCOR is likely to remain a model of international medical cooperation.

\section{Douglas Chamberlain Anthony J. Handley}




\section{Corresponding address}

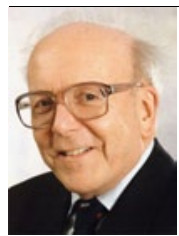

D. Chamberlain

Hove

United Kingdom

dac@dachamberlain.co.uk

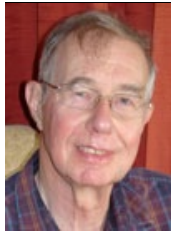

A.J. Handley

40 Queens Road, CO3

3PB Colchester

United Kingdom

tony.handley@btinternet.com

\section{Compliance with ethical guidelines}

Conflict of interest. D. Chamberlain and A.J. Handley state that there are no conflicts of interest.

This article does not contain any studies on humans or animals.

\section{Jahre \\ Notfall + Rettungsmedizin}

Im März 1998 erschien die erste Ausgabe der Zeitschrift Notfall + Rettungsmedizin . Anlässlich des 15- jährigen Bestehens möchten wir mit Ihnen in mehreren Beiträgen die Geschichte der Zeitschrift und den Wandel des Fachgebiets Revue passieren lassen. Der Button 15 Jahre Notfall + Rettungsmedizin weist Sie auf die entsprechenden Beiträge hin.



\section{Internationale Stimmen der Notfallmedizin}

Mit dem Beitrag von Prof.Douglas Chamberlain und Dr. Anthony J Handley (beide UK) dürfen wir Ihnen zwei weitere prominente Stimmen zur Entwicklung der Notfallmedizin präsentieren.

Professor Chamberlain gründete die erste Rettungssanitäter-Staffel in Europa und revolutionierte damit die präklinische Versorgung. Er ist Gründungsmitglied des Resuscitation Council (UK) und war Vorsitzender des European Resuscitation Council in (ERC). Später unterstützte er tatkräftig die Gründung des International Liaison Committee on Resuscitation (ILCOR). Heute ist er Editor Emeritus des Journals Resuscitation. Für seine Verdienste wurde er unter anderem zum "Commander of the Order of the British Empire" (CBE) ernannt.

Dr. Handley war Co-Vorsitzender des ILCOR und Vorsitzender des Resuscitation Council (UK). Er ist nach wie vor Mitglied des ERC und ist als Berater für zahlreiche Firmen und Institutionen tätig. 2004 wurde er wurde zum "Grand Knight of the Order of Livesavings" geschlagen. 